\title{
A model to predict the coastal sea level variations and surge
}

\author{
M. M. F. de Oliveira \& N. F. F. Ebecken \\ COPPE/Federal University of Rio de Janeiro, Brazil
}

\begin{abstract}
This paper presents a methodology to predict the coastal sea level variations and surge using a neural network model. Although drastic storm surge typically does not occur along the coastal waters of Brazil, these events can cause some damage to coastal regions. A strong storm surge occurred along the southeast coast of Brazil in March 1998 caused severe flooding in these coastal areas, destroying some coastline constructs. Operational forecasting of high sea levels (storm surges) might be important in the southeast coastal of Brazil, where there are registered sea level variations above the astronomical tide predictions that can consistently impact coastal zones in this area. The aim of this study is to develop an empirical prediction of storm surge by determining the relationship of the wind and pressure fields to storm surge. This proposed model can be used to as complement of the standard constant harmonic model to improve the prediction of the sea level variations.
\end{abstract}

Keywords: storm surge, sea level, neural networks.

\section{Introduction}

In the South Atlantic Ocean, along the Brazilian coastline, there are few tide gauge records with long series to analyze and predict surge events. Characteristics of the meteorological tide variations along the Southeast coast of Brazil have been studied by Marone and Camargo [18]. Castro and Lee [3] presented a study about the sea level fluctuations due to the wind-driven forces in the southeast continental shelf. Ribeiro [25] investigated a surge caused by the passage of a cyclone along the Rio de Janeiro coastline that raised the sea level $0.60 \mathrm{~m}$ above the mean sea level datum, causing damage to coastal communities along the Guanabara Bay. Netto and Lana [20] studied the superficial sediment 
characteristics of tidal flats in Paranaguá Bay. de Mesquita [7, 8] verified a similar behavior of the mean sea level oscillations along this area of the Brazilian coastline. Mantovanelli et al. [17] verified the tidal velocity and duration as a determinant of water transport and residual flow in Paranaguá Bay estuary. Dalazoana et al. [6] studied the mean sea level variations using longer tide gauge temporal series from Cananéia and Fiscal Island (State of Rio de Janeiro) tide gauge and satellite altimetry to establish analysis methods applicable to Brazilian vertical datum region.

The classical method of harmonic analysis is used to predict the astronomical tides. Tidal curves appear as periodic oscillations and can be described in terms of amplitude, period or frequency. The harmonic analysis is based in tidal variations represented by $\mathrm{N}$ harmonic constituents of the tide (Doodson and Warburg [9]). Normally, 365 days of hourly data at a point are needed to extract the constituents with adequate separation of closely spaced constituents using the least squares method. These constituents can then be used to provide reliable predictions for future tides at the respective point (Franco [12]).

Predictions for reference stations are prepared from the astronomical arguments, using local constituents determined by previous analysis and do not take into account meteorological influences. Thus, the observed and predicted values of the sea level are normally different. Numerical model developed to predict surges are still considered insufficient due to the complexity between the non-linear processes involved. These models require a large amount of tidal and meteorological data, collecting many factors as central pressure, speed of the cyclone, rainfall and coastal topography (Lee [16]).

Nowadays, the neural network model (NNM) has been widely applied to modeling non-linear dynamic systems, using time series that translate the physical relations between the input variables (predictors) and the phenomenon that will be modeled. Eisner and Tsonis [10] developed some methodologies for making short-term predictions of nonlinear time-series data, using a neural network model. These authors discuss the implication of these methodologies in the studies of weather and climate.

The NNM has some important characteristics such as generalization, parallelism, non-linearity, adaptability, robustness and others. These models have been used in some fields of science and engineering. Sztobryn [27] applied NNM in hydrological forecasting where the variation of water level is only wind generated. The results were successfully compared with observed sea level and others routine methods. Lee [16] applied a NNM for forecasting storm surge in Taiwan related to the passage of three typhoons over the region. The results indicate that NNM is efficiently capable of learning and predicting from these events. Tseng et al. [28] used a typhoon-surge forecasting model developed with a backpropagation neural network in the coastal of north-eastern Taiwan. To compare the better forecasting model, four models were applied and tested under different compositions of the input variables. For coastal and harbor engineering applications, Chang and Lin [4] simulated tides at multi-points considering tidegenerating forces. The NNM proposed is applicable for multi-points tidal prediction in which the tidal type is similar to that of the original point. 
The southeast coast of Brazil is sufficiently affected by cold fronts over 3-5 day periods. An important event that sometimes occurs due to combination of tides and surges is the rising of the sea level with waves that reached the coastline. There are few NNM applications to predict the variability of sea level along the Brazilian coastline focused on the surge events. The relationships describing the response of the coastal sea level due to the influence of cold fronts was analyzed using cross-correlations and spectral density between the tide gauge series and meteorological variables. Maxima values and time lags of both analyses were proposed as inputs of the sea level forecast model.

This paper presents a methodology to predict the coastal sea level variations and surge using a NNM.

\section{Study area}

The study area lies within the Cananéia estuary $\left(24^{\circ} 50^{\prime}-25^{\circ} 05^{\prime} \mathrm{S} / 47^{\circ} 45^{\prime}-\right.$ $\left.48^{\circ} 00^{\prime} \mathrm{W}\right)$; southeast coastal region of Brazil in São Paulo State. This region is located on the continental shelf, which is wider than the shelf of the northern coast. The average width and declivity, near Cananéia city in São Paulo State is about $218 \mathrm{~km}$ and $46 \mathrm{~cm} / \mathrm{km}$, respectively (Filippo [11]). The isobaths are oriented from southwest to northeast, parallel to the coastline with $45^{\circ}$ northern direction. It has wide coastal plains, long beach barriers, and large estuaries (Angulo and Lessa [1]). The Cananéia Estuary is an important biological reserve and contains federal and state Environmental Protected Areas (SMA, 1990/1996). This estuarine system covers an area of $135 \mathrm{~km}^{2}$ and is surrounded by a large mangrove area with high concentrations of nutrients (Besnard [2]).

The South American continent is affected by both tropical and extra tropical regions weather systems. The most severe weather systems in South America are cold fronts, intense extra tropical cyclones near the east coast causing intense winds, upper level cyclonic vortices (ULCV), in some cases responsible for cyclogenesis and frontogenesis, South Atlantic Convergence Zone (SACZ), squall lines, mesoscale convective complexes and the Low Level Jet (LLJ). This region is influenced by persistent high-pressure over the South Atlantic Ocean which enhances northeast flow across the area. This circulation is disturbed, periodically, by the passage of frontal systems caused by migrating anticyclones that move from the southwest across the northeast in the southeast coast of Brazil. In this region is verified the presence of strong cyclogenesis activity (Gan and Rao [14]; Seluchi [26]) associated with ULCV that reach through the South America west coast causing instability in the east and northeast sector. Gan \& Rao [14] has verified two regions of persistent cyclogenesis over South America; one over the San Matias Golf in Argentina $\left(42.5^{\circ} \mathrm{S}, 62.5^{\circ} \mathrm{W}\right)$ and another over Uruguay $\left(31.5^{\circ} \mathrm{S}, 55^{\circ} \mathrm{W}\right)$. The climate is subtropical humid and during the $\mathrm{El}$ Niño-South Oscillation (ENSO) phenomenon great climatic disturbances occur in this region, leading to abundant rain. 


\section{Statistical analysis}

The atmospheric pressure, wind and tide gauge time series were analyzed statistically by estimating the center of the distribution (mean and median), variances, standard deviation, asymmetry and kurtosis. From the percentiles analyses could be identified few outliers in the sea level record with the box plot graphic. They were substituted with the average values between the previous and the following hourly data. Before fitting, both series were used for the period from January 1997 to December 1998 to study the coastal sea level response related to the meteorological conditions as well as the behavior of the coastal sea level in this Brazilian region.

\subsection{Filtering data using a low-pass filter}

The present study was focused on the oscillations in sea level caused by frequency lower than astronomical driven forces related to the passage of frontal systems which have periods around 3 to 5 days. Tides and inertial motions usually cause a high-frequency noise in sea level records used to analyze lowfrequency motion in the ocean. To eliminate diurnal and shorter-periods tides oscillations from input data set, the Thompson low-pass filter, a symmetric digital filter, was used.

Hourly observed sea level records were then filtered to remove the oscillations or noises related to tidal frequencies. For the reanalysis data set was used the same filter, considering the 6-hourly intervals. After filtering, the hourly sea level series was replaced at 6-hourly interval as the reanalysis data and so, both data sets could be compared for the same time interval and frequencies.

\subsection{Series analysis in the time and frequency domain}

Storm surge is usually considered to be driven by two processes: the extreme wind stress and atmospheric pressure. Therefore, cross-correlations between the filtered sea level, atmospheric pressure, zonal and meridional wind stresses were calculated.

\section{Neural Network Modelling (NNM)}

In this paper, different training methods were applied to find the best performance: Radial Basis Functions (RBF), a network particularly adapted to approximation function. The hidden layer is defined by radial basis functions and the learning fits a non-linear surface accordingly some stochastic criteria; Generalized Regression Neural Network (GRNN), a method for estimating the joint probability density function (pdf) of $\mathrm{x}$ and $\mathrm{y}$ as in standard regression technique, given only a training set (Cigizoglu and Alp [5]); and NN feed forward - MLP. It was used the supervised learning and back propagation algorithm.

All samples were used with intervals of 6-hourly (LT) between the observations and this data set was selected in 50\% for training, $25 \%$ for testing 
and $25 \%$ for validation. The input variables for the $\mathrm{NN}$ training were atmospheric variables, filtered sea level series of previous hours, and observed wind for the actual time.

\section{Statistical analysis results}

The filtered records generated the time series of the sea level response in low frequency related with the meteorological systems which were used in the NN (Fig. 1).

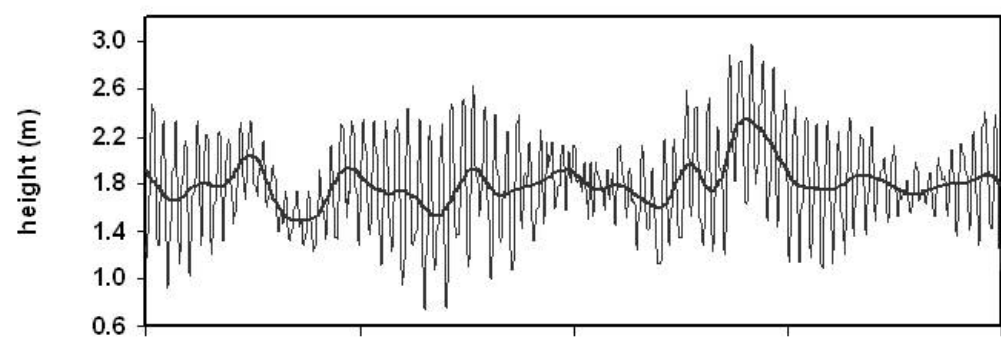

January 15, 1998 January 25, 1998 February 04, 1998 February 14, 1998 February 24, 1998

- Observed sea level

- Filtered sea level

Figure 1: $\quad$ Oscillations of observed and filtered sea level time series.

In order to verify the inter-correlations of the sea level response and meteorological variables in the same frequency, values of cross-spectral densities and coherence between the series were analyzed. It was found that peaks of energy and high coherence for periods from 5 to 3 days were related to passages of cold fronts over the region.

\section{NNM performance}

The maximum values of cross-correlations described previously were used as input model. Then, a time lag was considered with respect to the sea level response and the meteorological variables. Autocorrelations of the low frequency sea level and wind speed for the current time was also used. Therefore, pressure, zWs, mws, 18, 12, and 6-hourly filtered sea level and wind speed predictors) as input vectors. The filtered sea level relating to 6-hourly after was used as output variable.

Table 1 shows the best performances of the NNM with the correlation coefficients (r). The MLP with 7-14-1 layers produced the best results.

The back propagation algorithm was used for the NNM training. The activation function used in the hidden and output units was the hyperbolic tangent function. Table 2 shows the correlation coefficients to the selected pairs for training, testing and validation for 6, 12, 18 and 24-hourly simulations. In both the stages a high correlation was observed. 
Table 1: $\quad$ Correlation Coefficients (r).

\begin{tabular}{|l|c|c|}
\hline NNM & Training (\%) & Validation (\%) \\
\hline RBF & 95.36 & 93.63 \\
\hline GRNN & 98.18 & 97.65 \\
\hline MLP(7-9-1) & 95.73 & 93.83 \\
\hline MLP(7-11-1) & 95.81 & 94.17 \\
\hline MLP(7-14-1) & 99.90 & 99.87 \\
\hline
\end{tabular}

Table 2: $\quad$ Correlation coefficients (r) for $6,12,18$ and 24 hourly simulations.

\begin{tabular}{|c|c|c|c|}
\hline Time lag (h) & Training (\%) & Testing (\%) & Validation (\%) \\
\hline 6 & 99.91 & 99.98 & 99.87 \\
\hline 12 & 98.98 & 98.75 & 98.44 \\
\hline 18 & 95.49 & 94.32 & 93.64 \\
\hline 24 & 88.19 & 85.06 & 83.08 \\
\hline
\end{tabular}

MLP (7-14-1) for forecasting the sea level variations for 6-hourly time lags presents accurate results. The performance of NN to forecast the sea level variations was satisfactory enough (correlation $=99.9 \%$ ) for 6-hourly time lags. Fig. 2 shows the comparison between $\mathrm{NN}$ generalization (validation) to predict the variations of the low frequency sea level and the target (filtering data set). It is observed that the two curves are quite similar, being in accordance with the statistic results shown in Table 2 .

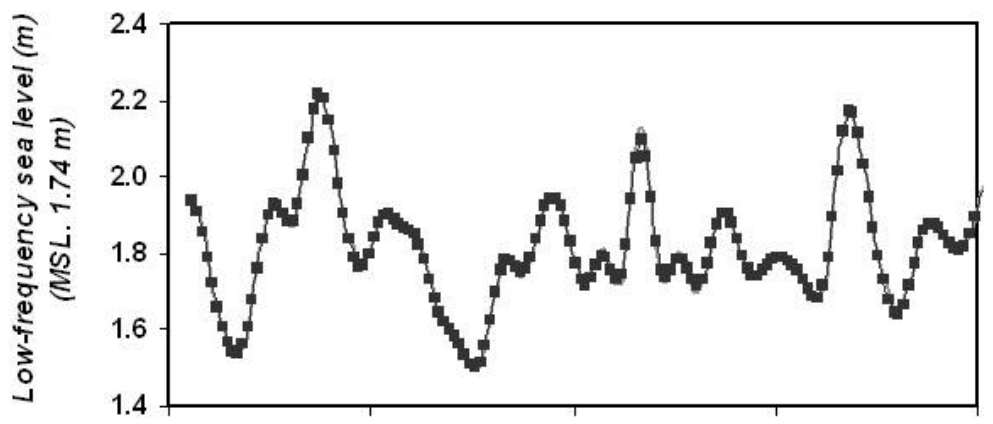

April 25, 1998 May 05, 1998 May 15, 1998 May 25, 1998 June 04, 1998

- target

$\rightarrow M L P$ forecast

Figure 2: Oscillations of the low-frequency sea level and simulated MLP curve.

Learning rate and momentum parameters affect the speed of the convergence of the back propagation algorithm. The stopping criterion was based on the error to be minimized to improve the performance of the network. The model attained the best performance for 700 epochs in which the training error is 0,008276 and validation error is 0,008531 with learning rate of 0.01 and momentum of 0.9 .

The scatter plots shown in Fig. 3 have small disparity illustrating that NN has a small error in learning stage than in the validation stage according to the 
correlation coefficients present in Table 2. This is a common result in establishing a NN. Normally the simulation performance of predictors is evaluated by the root mean square (RMS) or the square of correlation coefficient (R2) that is called coefficient of determination. Small RMS and large $\mathrm{R}^{2}$ values indicate that the simulation performance is good (Chang 2006).

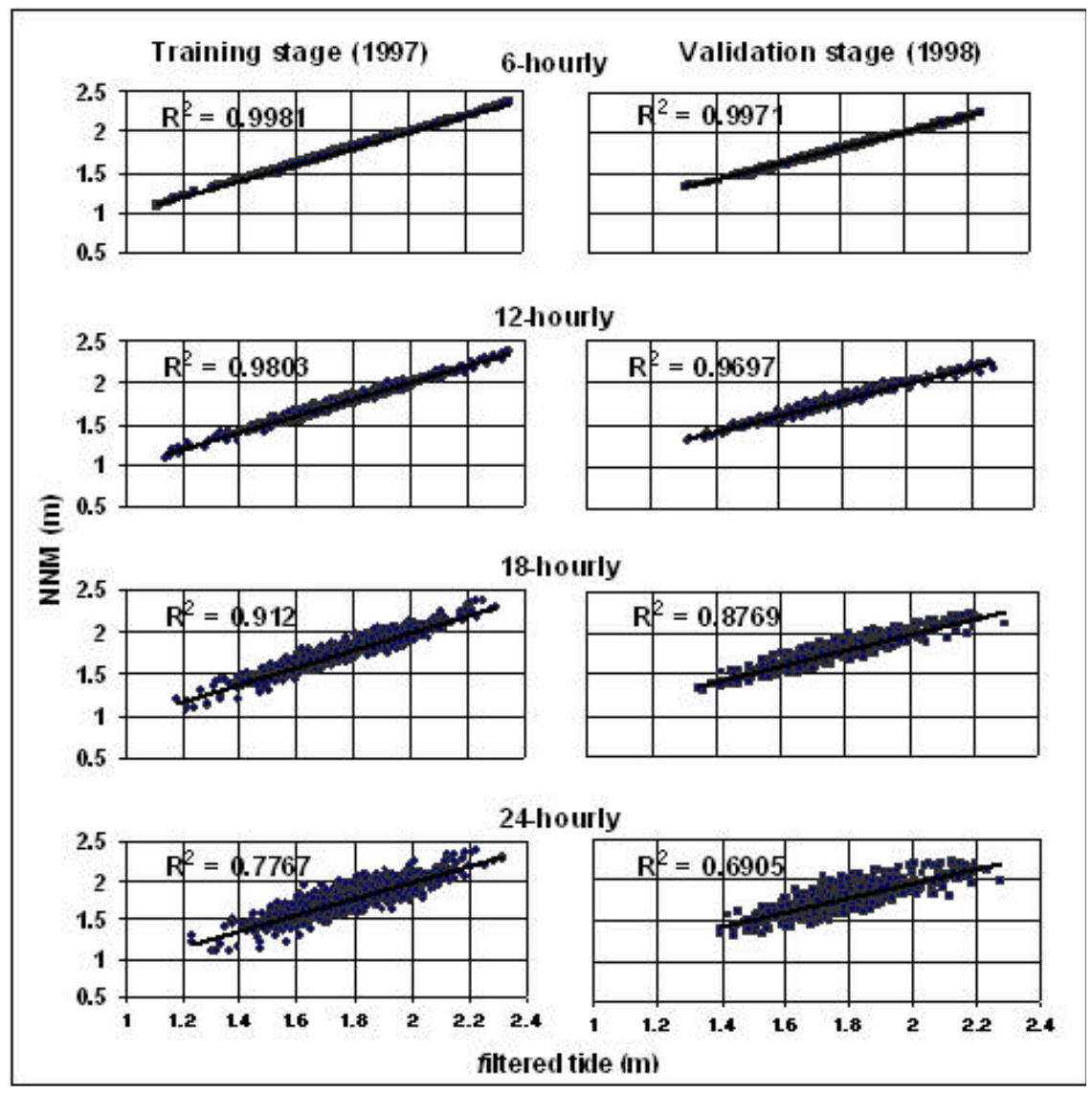

Figure 3: $\quad$ Scatter plots of simulated and filtered sea level data in training stage for 1997 and validation stage for 1998.

The left column of this figure shows the target and desired output simulated by NN in training stage for 1997. This column indicates that there is little disparity between filtered and simulated values for 6 and 12-hourly training in which $\mathrm{R}^{2}$ is 0.9981 and 0.9803 , respectively. The $\mathrm{R}^{2}$ values for 18 and 24-hourly are around 0.912 and 0.7767 , respectively, showing that the NNM preserves the influences of physical process such as pressure and wind in the sea level variations. The right column shows the scatter plots for 1998 in the validation stage. Small differences between the two stages are verified. The $\mathrm{R}^{2}$ values for 6 , 12 and 18-hourly present similar results with the learning stage. For 24-hourly 
forecasting, the $\mathrm{R}^{2}$ presented values lower than for testing stage. It can be related to the correlation between the predictors and output.

Strong $\left(\sim 15 \mathrm{~m} . \mathrm{s}^{1}{ }^{1}\right)$ south-westerly (190-260 degrees) winds blowing during 3 to 5 days, over the ocean parallel the coastline, is the most conducive wind vector for producing storm surge along the southeast Brazilian coast.

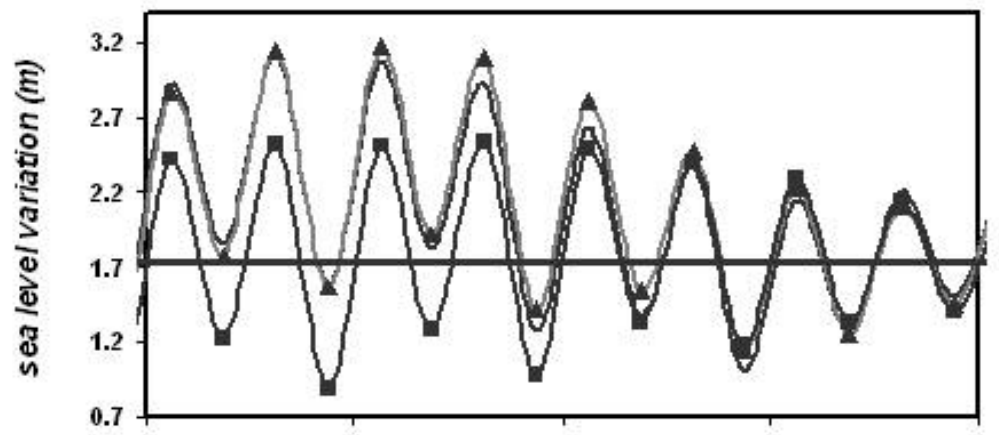

March 26, 1998 March 27, 1998 March 28, 1998 March 29, 1998 March 30, 1998
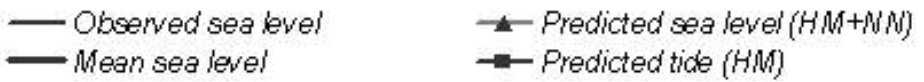

Figure 4: Comparison between observed coastal sea level and predicted with both models. It is verified that the HM undervalues the prediction for a storm surge on 26-28 March 1998.

Fig. 4 shows the curves of the sea level variation related to the storm surge occurred on 26-28 March 1998 in southeast coastal Brazil. The value of the peak of the high water level on 26 March was $3.13 \mathrm{~m}$ and the predict tide with Harmonic Model (HM) was $2.53 \mathrm{~m}$. The difference between the maxima peaks was around $0.60 \mathrm{~m}$, characterizing the occurrence of a surge in this region. The value predicted by NNM was around $0.63 \mathrm{~m}$. Therefore, the value obtained with both models (HM + NNM) was around $3.16 \mathrm{~m}$. It can also be verified in the Figure that some peaks of the high water predicted with both models are above the observed sea level. The values of the low water level are quite similar (Fig. 4).

\section{Conclusion}

Conventional numerical model developed to predict surges are still considered insufficient due to the complexity between the non-linear processes involved. In this paper, an alternative methodology based on the structure of neural network model to predict coastal sea level variations related to meteorological events was proposed.

Pre-processing of the data series in the time and frequency domain allowed defining the input of the neural network model. Maxima correlations in the physical process could determine the time lag between the meteorological variables and the sea level response. 
The results indicate that the MLP architecture of the network developed in this work could generalize satisfactorily the non-linear behavior of the sea level fluctuations due to the interactions ocean-atmosphere at Cananéia tide gauge station. This model presented the best performance with correlation coefficient around $99 \%$ for 6-hourly time lag simulation and it can be efficient to forecast storm surge. The results obtained for 24-hourly time lag simulations around $83 \%$ of correlation coefficient (r) suggest that this model could be still used for forecasting the low-frequency sea level to this time lag with good performance. Forecasting for periods larger than 24-hourly could be improved, considering hydrodynamic variables such as river discharges. The results indicate that the NNM can also be useful as complement for the standard harmonic model (HM) and thus to improve the sea level forecast.

The proposed NNM for predicting the surge level can be further applied to other locations along the Brazilian coast or in others sites in the world. In addition, this NNM could be developed in conjunction a numerical ocean model (e.g. Princeton Ocean Model - POM) to improve forecasting water levels at the key locations.

\section{Acknowledgements}

The authors acknowledge the Brazilian Research Agencies CNPq and FAPERJ for their financial support of this work.

\section{References}

[1] Angulo, R. J. \& Lessa, G. C., The Brazilian sea-level curves: A critical review emphasis on curves from Paranagua and Cananeia regions. Mar. Geol., 140, 141-166, 1997.

[2] Besnard, W., General aspects about the Cananeia-Iguape region-1. Institute. Paulista Oceanogr., 1, 9-26, 1950.

[3] Castro, B. M., \& Lee T. N., Wind-forced sea level variability on the southeast Brazilian shelf. J. Geophsys. Res., 100, 16 045-16 056, 1995.

[4] Chang, H.-K., \& Lin L.-C., Multi-point tidal prediction using artificial neural network with tide-generating forces. Coastal Eng., 53, 857-864, 2006.

[5] Cigizoglu, H. R., \& Alp M., Generalized regression neural network in modelling river sediment yield. Adv. Eng. Software, 37, 63-68, 2006.

[6] Dalazoana, R., Luz, R. T. \& de Freitas S. R. C., Mean sea level studies from tide gauge and satellite altimetry time series looking for the integration of Brazilian Network to SIRGAS. Rev. Bras. Cartogr., 57, 140153, 2005.

[7] de Mesquita, A. R., Tides: Circulation and sea level in the southeastern coast of Brazil). http:// www.mares.io.usp.br/sudeste/sudeste.html, 2008.

[8] de Mesquita, Sea level variations along the Brazilian coast: A short review. Brazilian Symp. on Sandy Beache. http:/www.mares.io.usp.br/praias/ praias.html. 
[9] Doodson, A. T., and H. D. Warburg, Manual of Tides of the Admiralty). 2nd ed. Brazilian Navy, 1944.

[10] Eisner, J. B., \& Tsonis A. A., Nonlinear prediction, chaos and noise. Bull. Atner. Meteor. Soc., 73, 49-60, 1992.

[11] Filippo, A. M., Variability of sea level as a function of meteorological events of low frequency. Ph.D. thesis, Fluminense Federal University, Rio de Janeiro State, Brazil, 2003.

[12] Franco, A. S., Tides: Fundamentals Analysis and Prediction. IPT, 1981.

[13] Fu, L.-M., Neural Networks in Computer intelligence. McGraw-Hill, 1994.

[14] Gan, M. A., \& Rao V. B., Surface cyclogenesis over South America, Mon. Wea. Rev., 119, 1293-1302, 1991.

[15] Kistler, R. et al., The NCEP-NCAR 50-Year Reanalysis: Monthly means CD-ROM and documentation. Bull. Amer. Meteor. Soc., 82, 247-267, 2001.

[16] Lee, T. L., Neural network prediction of a storm surge. Ocean Eng., 33, 483-494, 2006.

[17] Mantovanelli, A. et al., Combined tidal velocity and duration asymmetries as a determinant of water transport and residual flow in Paranagua Bay estuary. Estuarine Coastal Shelf Sci., 59, 523-537, 2004.

[18] Marone, E., \& Camargo R., Meteorological tides in the coast of the state of Parana: The event of 18 August 1993. Nerntica, 8, 1-2,1994.

[19] McPhaden, M. El Nino: The child prodigy of 1997-98. Nature, 398, 559$562,1999$.

[20] Netto. S. A., \& Lana P. C., Influence of Spartina Alterniflora on superficial sediment characteristics of tidal flats in Paranagua Bay (South-eastern. Brazil). Estuarine Coastal Shelf Sci., 44, 641-648, 1997.

[21] Paiva. A. M., Study of sea level variations in Arraial do Cabo, Rio de Janeiro. his Research Rep. COPPE. Federal University of Rio de Janeiro, 1993.

[22] Pore, N. A., The relation of wind and pressure to extratropical storm surge at Atlantic City. J. Appl. Meteor., 3, 155-163, 1964.

[23] Pugh, D. T., Tides, Surges and Mean Sea Level. John Wiley and Sons, 1987.

[24] Rao, V. B., \& Rada K., Characteristics of rainfall over Brazil: Annual variations and connections with the southern oscillation. Theor. Appl. Clitnatol., 42, 81-91, 1990.

[25] Ribeiro, C. E. P., A new adaptive technique for directional analysis of waves. Proceedings of 11 Meeting on Waves and Seas, IEAPM, 182-193, 1997.

[26] Seluchi, M. E., Diagnostics and prognostics of synoptic situations conducive to cyclogenesis on the east of South America Geofis. Int., 34, $171186,1995$.

[27] Sztobryn, M., Forecast of storm surge by means of artificial neural network. J. Sea Res., 49, 317-322, 2003.

[28] Tseng, C. M., Jan C. D., Wang J. S. \& Wang C. M., Application of artificial neural network in typhoon surge forecasting. Ocean Eng., 34, 1757-1768, 2007. 